\title{
Comparable Periprocedural Outcomes of Percutaneous Coronary Intervention in Male and Female Patients with Type C Lesions
}

\author{
Narapureddy Dhananjaneya Reddy ${ }^{1}$ Nemani Lalita ${ }^{1}$ \\ ${ }^{1}$ Department of Cardiology, Nizam's Institute of Medical Sciences \\ (NIMS), Punjagutta, Hyderabad, India \\ Address for correspondence N. Dhananjaneya Reddy, MBBS, MD, \\ Department of Cardiology, Nizam's Institute of Medical Sciences \\ (NIMS), Punjagutta, Hyderabad 500082, India \\ Indian J Cardiovasc Dis Women-WINCARS 2017;2:21-24. \\ (e-mail: danni.reddy@gmail.com).
}

\begin{abstract}
Background Percutaneous coronary intervention $(\mathrm{PCl})$ in type $\mathrm{C}$ lesions has low success and has high procedural risk. We aimed at studying the outcomes of $\mathrm{PCl}$ in patients with type $C$ lesions.

Material and Methods Total 180 patients with type $\mathrm{C}$ lesions who underwent $\mathrm{PCI}$ from January 2007 to December 2014 were taken into study and analyzed.

Results Of 180 patients, 141 (78.3\%) were males and 39 (21.7\%) were females. Mean hemoglobin concentration, mean serum triglycerides, and mean estimated glomerular filtration rate were significantly lower in females compared with males. Seventy-seven (42.8\%) patients had lesions in right coronary artery, 67 (37.2\%) had lesions in left anterior descending coronary artery, 31 (17.2\%) had lesions in left circumflex artery, and $5(2.8 \%)$ had left main coronary artery disease. Complex lesions were common in males. Chronic total occlusion (СTO) was found in 140 cases and other than CTO of type $C$ lesions in 40 patients. Predilatation was done in 169 (93.9\%) patients. Successful $\mathrm{PCl}$ was done in 157 (87.2\%) patients. Lesion could not be crossed in 11 (6.1\%) patients.

Keywords

- acute coronary syndrome

- percutaneous coronary intervention

- type C lesions Only plain old balloon angioplasty could be done in $9(5 \%)$ patients. Other complications occurred in $3(1.67 \%)$ patients. There was no difference between female and male patients in requiring predilatation or crossing the lesion or in not being able to deliver the stent.

Conclusion $\mathrm{PCl}$ success rate among patients with type $\mathrm{C}$ lesions was $87.2 \%$ with lowcomplication rate in the present era. There was no difference in between female and male patients in success rate or complications.
\end{abstract}

\section{Introduction}

Percutaneous coronary intervention (PCI) is a reliable and effective therapeutic option for patients with coronary artery disease (CAD) and has become one of the most widely applied treatments in present-day cardiology. Type $C$ coronary lesions represent a complex angiographic scenario, although they are rather common in the daily clinical practice of PCI. This article is aimed to report the outcomes of PCIs performed in patients with type $\mathrm{C}$ lesions.

DOI https://doi.org/ 10.1055/s-0037-1607271.

\section{Materials and Methods}

It is an observational study of 180 patients with type $C$ lesions who underwent PCI were taken into study and analyzed. Data were collected from records of our institute from January 2007 to December 2014. We collected the demographics data, clinical presentation, electrocardiographic (ECG) and two-dimensional (2D) echocardiographic findings, and details of coronary angiography (CAG) and PCI with in-hospital events. 
Definition of type C lesion: Lesions with type C are $>20 \mathrm{~mm}$ diffuse, excessive tortuosity of proximal segment, extremely angulated segments, $\geq 90$ degrees, total occlusion $>3$ months old and/or bridging collaterals, inability to protect major side branches, degenerated vein graft with friable lesions as per American College of Cardiology/American Heart Association (ACC/AHA) guidelines. ${ }^{1}$

PCI success may be defined by angiographic, procedural, and clinical criteria. Angiographic success in a stented artery is defined as minimum stenosis diameter reduction to $<20 \%$. The definition of procedural success is angiographic success without in-hospital major clinical complications (e.g., death, myocardial infarction [MI], emergency coronary artery bypass surgery) during hospitalization. Clinical success is defined as anatomical and procedural success with relief of signs and/or symptoms of myocardial ischemia after recovery from the procedure. The long-term clinical success requires that the patient have persistent relief of signs and symptoms of myocardial ischemia for $>6$ months. $^{2}$

\section{Statistical Analysis}

Statistical analysis was performed with Minitab statistical software (Minitab Inc., Pennsylvania, Philadelphia, United States). The study population was subdivided into two groups according to sex: males and females. Continuous parameters are presented as mean \pm standard deviation (SD) and compared using the $t$-test or Wilcoxon rank-sum test as appropriate. Nominal parameters are presented as percentages and compared using Fischer's exact test. Differences were statistically significant when the respective $p$ values were $<0.05$.

\section{Results}

A total of 180 patients with type $C$ lesions who underwent $\mathrm{PCl}$ were included in the study, of whom, 141 (78.3\%) were males and 39 (21.7\%) were females. Mean age of presentation was slightly more in females compared with males ( $58.7 \pm 10.6 \mathrm{vs}$. $56.1 \pm 10.9 ; p=0.17$ ). The prevalence of hypertension and diabetes was greater in females compared with males. Smoking history was present in $32 \%$ of males and only $2.6 \%$ of females $(p=0.00)$. The presentation of patients, that is, chronic stable angina (CSA) versus acute coronary syndrome (ACS) among males was $51.7 \%$ versus $48.3 \%$ whereas in females it was $35.8 \%$ versus $64.2 \%$. Left ventricular (LV) dysfunction was present more in males compared with females, which is not statistically significant ( $44.6 \%$ vs. $35.8 \% ; p=0.31$ ). History of prior PCI was present in $9.2 \%$ of males and $12.5 \%$ of females $(p=0.54)$. History of prior coronary artery bypass grafting (CABG) was present in $10.6 \%$ of males and $2.56 \%$ of females $(p=0.02)(-$ Table 1, - Fig. 1$)$.

Mean hemoglobin concentration (in $\mathrm{mg} / \mathrm{dL}$ ) was less in females compared with males $(11.44 \pm 1.83$ vs. $13.11 \pm 2.06$; $p=0.00$ ). Lipid profile levels were almost comparable between males and females except for serum triglycerides (in $\mathrm{mg} / \mathrm{dL}$ ), which were significantly higher in males compared with females $(155.4 \pm 68.6$ vs. $84.67 \pm 8.14 ; p$ value $=0.01)$. Mean estimated glomerular filtration rate (eGFR) (in $\mathrm{mL} / \mathrm{min} / 1.73 \mathrm{~m}^{2}$ )
Table 1 Baseline characteristics of male and female PCI done patients

\begin{tabular}{|l|l|l|l|}
\hline Variable & Males & Females & $p$ Value \\
\hline No. of cases & $141(78.3 \%)$ & $39(21.7 \%)$ & - \\
\hline Age (y) & $56.1 \pm 10.9$ & $58.7 \pm 10.6$ & 0.17 \\
\hline HTN (\%) & $86(60.9 \%)$ & $28(71.7 \%)$ & 0.19 \\
\hline DM (\%) & $56(39.7 \%)$ & $19(48.7 \%)$ & 0.31 \\
\hline Smoking (\%) & $45(31.9 \%)$ & $1(2.56 \%)$ & 0.000 \\
\hline CSA (\%) & $73(51.7 \%)$ & $14(35.8 \%)$ & 0.07 \\
\hline LV dysfunction (\%) & $63(44.6 \%)$ & $14(35.8 \%)$ & 0.31 \\
\hline Prior PCI (\%) & $13(9.2 \%)$ & $5(12.8 \%)$ & 0.54 \\
\hline Prior CABG (\%) & $15(10.6 \%)$ & $1(2.56 \%)$ & 0.02 \\
\hline
\end{tabular}

Abbreviations: CABG, coronary artery bypass grafting; CSA, chronic stable angina; DM, diabetes mellitus; HTN, hypertension; LV, left ventricular; $\mathrm{PCl}$, percutaneous coronary intervention.

was also significantly lower in females compared with males $(73.9 \pm 25.1$ vs. $96.8 \pm 26.4, p$ value $=0.00)(-$ Table 2$)$.

Seventy-seven $(42.8 \%)$ patients had lesions in the right coronary artery (RCA), 67 (37.2\%) had lesions in the left anterior descending (LAD) coronary artery, 31(17.2\%) had lesions in the left circumflex artery (LCX), and 5 (2.8\%) had disease in the left main coronary artery (LMCA). Ostial lesion was found in 31 patients of whom nearly half (48.4\%) had LAD lesion. Calcified lesions were more common in males compared with females although it is not statistically significant ( $22.6 \%$ vs. $15.3 \% ; p=0.28$ ). Thrombus containing and bifurcation lesions were also more common in males. Ulcerated lesions were also more common in males than females $(18.4 \%$ vs. $7.6 \%, p=0.04)$ (-Table 3, -Fig. 2). Chronic total occlusion (CTO) was found in 140 cases and other than CTO type C lesions in 40 patients. CTO PCI was done more in female patients $(75 \%$ vs. $87.5 \%, p=0.05)$.

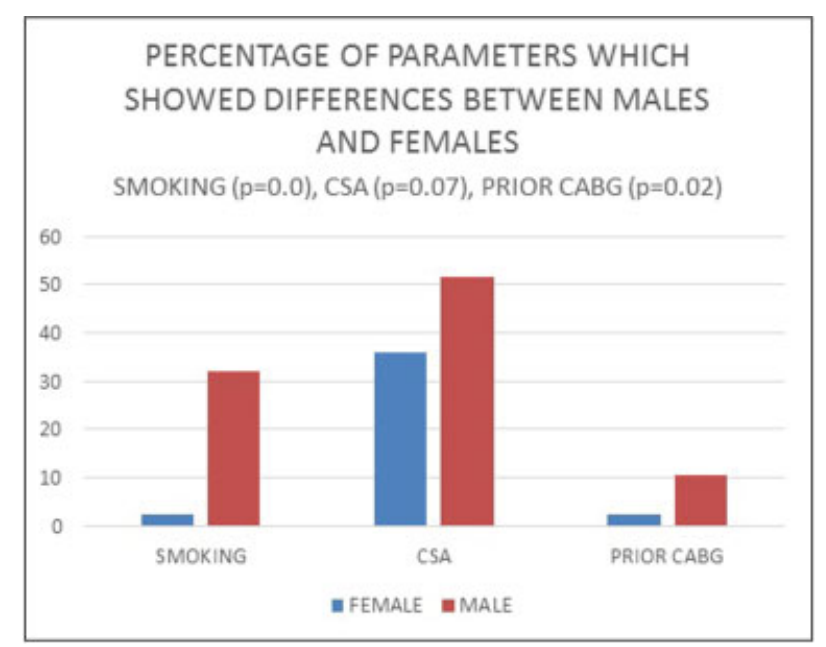

Fig. 1 Bar diagram showing the differences in historical parameters (percentages) in both sexes. CABG, coronary artery bypass grafting; CSA, chronic stable angina. 
Table 2 Comparison of laboratory parameters in male and female patients

\begin{tabular}{|l|l|l|l|}
\hline Variable & $\begin{array}{l}\text { Males } \\
\text { (Mean } \pm \text { SD) }\end{array}$ & $\begin{array}{l}\text { Females } \\
\text { (Mean } \pm \text { SD) }\end{array}$ & $p$ Value \\
\hline Systolic BP $(\mathrm{mm} \mathrm{Hg})$ & $138.6 \pm 27.2$ & $140.8 \pm 29.0$ & 0.67 \\
\hline Diastolic BP $(\mathrm{mm} \mathrm{Hg})$ & $78.0 \pm 11.0$ & $79.0 \pm 13.5$ & 0.69 \\
\hline Hemoglobin $(\mathrm{mg} / \mathrm{dL})$ & $13.11 \pm 2.06$ & $11.44 \pm 1.83$ & 0.000 \\
\hline Packed cell volume $\%)$ & $39.06 \pm 6.12$ & $34.33 \pm 5.22$ & 0.000 \\
\hline $\begin{array}{l}\text { Platelet count } \\
\left.\text { (lakh/mm }{ }^{3}\right)\end{array}$ & $2.418 \pm 0.813$ & $2.467 \pm 0.822$ & 0.74 \\
\hline RBS $(\mathrm{mg} / \mathrm{dL})$ & $148.7 \pm 71.6$ & $157.9 \pm 65.6$ & 0.44 \\
\hline $\begin{array}{l}\text { Total cholesterol } \\
\text { (mg/dL) }\end{array}$ & $153.9 \pm 50.1$ & $138.3 \pm 23.6$ & 0.48 \\
\hline HDL $(\mathrm{mg} / \mathrm{dL})$ & $39.5 \pm 10.4$ & $45.7 \pm 12.9$ & 0.52 \\
\hline LDL $(\mathrm{mg} / \mathrm{dL})$ & $80.8 \pm 41.5$ & $75.7 \pm 11.5$ & 0.73 \\
\hline Triglycerides $(\mathrm{mg} / \mathrm{dL})$ & $155.4 \pm 68.6$ & $84.67 \pm 8.14$ & 0.011 \\
\hline eGFR (mL/mim/1.73 $\mathrm{m}^{2}$ ) & $96.8 \pm 26.4$ & $73.9 \pm 25.1$ & 0.000 \\
\hline
\end{tabular}

Abbreviations: BP, blood pressure; eGFR, estimated glomerular filtration rate; HDL, high-density lipoprotein; LDL, low-density lipoprotein; RBS, random blood sugar; SD, standard deviation.

Table 3 Lesion characteristics

\begin{tabular}{|l|l|l|l|}
\hline Variables & Males & Females & $p$ Value \\
\hline Ostial description & $21(14.8 \%)$ & $10(25.6 \%)$ & 0.15 \\
\hline $\begin{array}{l}\text { Calcification } \\
\text { description }\end{array}$ & $32(22.6 \%)$ & $6(15.3 \%)$ & 0.28 \\
\hline $\begin{array}{l}\text { Thrombus } \\
\text { description }\end{array}$ & $21(14.8 \%)$ & $3(7.6 \%)$ & 0.16 \\
\hline Ulcer lesion & $26(18.4 \%)$ & $3(7.6 \%)$ & 0.04 \\
\hline $\begin{array}{l}\text { Bifurcation lesion } \\
\text { description }\end{array}$ & $21(14.8 \%)$ & $3(7.6 \%)$ & 0.16 \\
\hline CTO & $105(75 \%)$ & $35(87.5 \%)$ & 0.05 \\
\hline
\end{tabular}

Abbreviation: СTO, chronic total occlusion.

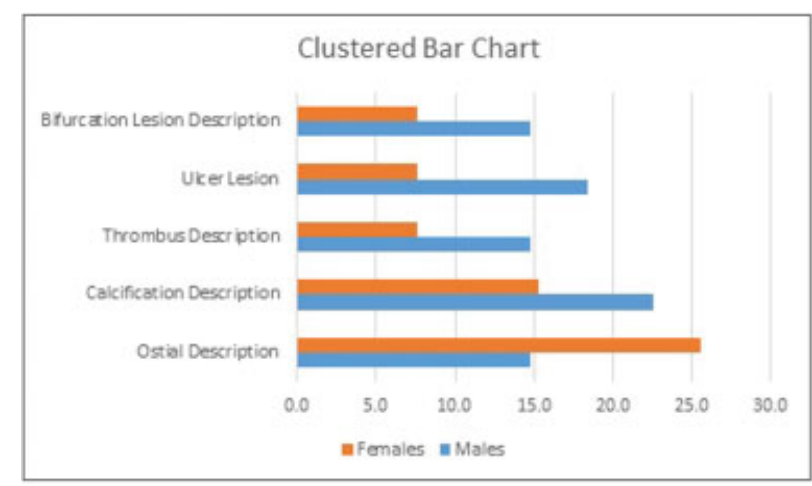

Fig. 2 A clustered bar chart demonstrating comparable values of both sexes across a coronary artery lesion characters.
Table 4 Final periprocedural result in study population

\begin{tabular}{|l|l|}
\hline Result & $\begin{array}{l}\text { Number of cases } \\
(\%)\end{array}$ \\
\hline Successful PCI & $157(87.2 \%)$ \\
\hline Could not cross the lesion & $11(6.1 \%)$ \\
\hline Only POBA & $9(5 \%)$ \\
\hline Other periprocedural complications & $3(1.6 \%)$ \\
\hline
\end{tabular}

Abbreviations: $\mathrm{PCl}$, percutaneous coronary intervention; $\mathrm{POBA}$, plain old balloon angioplasty.

Successful PCI was done in 157 (87.2\%) patients. Predilatation was done in 169 (93.9\%) patients. Lesion could not be crossed in $11(6.1 \%)$ patients. Only plain old balloon angioplasty (POBA) was done in $9(5 \%)$ patients ( - Table 4 ) as stent could not be delivered. Other complications occurred in $3(1.67 \%)$ patients (details are given as follows). There was no difference between female and male patients in requiring predilatation or crossing the lesion or not able to deliver the stent.

Three (1.6\%) patients had other complications. One patient succumbed to death due to access site hematoma and contrastinduced nephropathy. One patient developed complete heart block (CHB) and cardiogenic shock. One patient developed dissection of the vessel, and wire could not be crossed, which led to abandoning of procedure ( $\boldsymbol{- T a b l e} \mathbf{4}$ shows this case as failure to cross the lesion). One patient had underexpansion of stent. However, with subsequent NC high-pressure dilatation, stent expanded well. One patient had pinching of diagonal after stent deployment, which could not be stented ( - Table 5 ).

\section{Discussion}

Traditionally type C lesions have a low success rate of $<60 \%$ and have a high risk. ${ }^{1}$ The success rate for type $C$ lesions in our study is $87.2 \%$. Ellis et al ${ }^{3}$ evaluated these criteria in $>1,000$ lesions from the Multi-vessel Angioplasty Prognostic study. They found that angulated stenosis, high-grade stenosis, CTO lesions, bifurcation stenosis, and male sex were associated with reduced success rates; the other factors in the AHA/ACC system were not predictive. Overall angiographic success occurred in just $82.6 \%$ of patients, reflecting the state of the

Table 5 Other periprocedural complications of study population

\begin{tabular}{|l|l|}
\hline Event & Number of cases (\%) \\
\hline Death $^{\mathrm{a}}$ & $1(0.5 \%)$ \\
\hline Hematoma $^{\mathrm{a}}$ & $1(0.5 \%)$ \\
\hline Contrast-induced nephropathy $^{\mathrm{a}}$ & $1(0.5 \%)$ \\
\hline CHB $^{\mathrm{a}}$ & $1(0.5 \%)$ \\
\hline Cardiogenic shock $^{\mathrm{a}}$ & $1(0.5 \%)$ \\
\hline Coronary artery dissection $^{\mathrm{b}}$ & $1(0.5 \%)$ \\
\hline Pinching of diagonal & $1(0.5 \%)$ \\
\hline
\end{tabular}

${ }^{\mathrm{a}}$ All events occurred in the same patient.

bSame patient had failure to cross the lesion. 
art of that era. They confirmed the usefulness of the ACC/AHA classification for predicting success in general but found that actual rates of success ranged from $92 \%$ for type A lesions to $60 \%$ for type $C$ lesions.

Tan et $\mathrm{al}^{4}$ performed a careful prospective evaluation of 729 patients, using two independent observers unaware of $\mathrm{PCl}$ outcome at the time of the lesion. Type $\mathrm{C}$ characteristics had a success rate ranging from 57 to $88 \%$ and an abrupt closure rate ranging from 0 to $16 \%$. Longer lesions, calcified lesions, diameter stenosis of 80 to $99 \%$, and presence of thrombus were predictive of a lower success rate. Longer lesions, angulated lesions, diameter stenosis of 80 to $99 \%$, and calcified lesions were predicted an abrupt closure. The investigators concluded that the AHA/ACC classification scheme was "outdated and needed to be changed for application in current angioplasty practice."

Zaacks et $\mathrm{al}^{5,6}$ evaluating patients angioplastied from 1994 to 1996 in a single center showed that the success rates with class $\mathrm{C}$ lesions was $88.2 \%$. Krone et $\mathrm{al}^{7}$ showed a success rate of $84.1 \%$ for type C lesions.

In PROGRESS CTO (Prospective Global Registry for the Study of Chronic Total Occlusion Intervention), factors for prediction of periprocedural complications in CTO PCI were studied. $^{8}$ Three factors were independent predictors of complications and were included in the score: patient age $>65$ years, +3 points (odds ratio $[\mathrm{OR}]=4.85$, confidence interval [CI]: $1.82-16.77$ ); lesion length $\geq 23 \mathrm{~mm},+2$ points $(\mathrm{OR}=3.22, \mathrm{CI}: 1.08-13.89)$; and use of the retrograde approach +1 point $(\mathrm{OR}=2.41, \mathrm{CI}: 1.04-6.05)$. Christopoulos et al used J-CTO score for prediction of periprocedural complications in CTO PCI. ${ }^{9}$ In the present study, we evaluated the clinical profile, procedural details, and the success rate of $\mathrm{PCI}$ of patients with type $\mathrm{C}$ coronary lesions, which included the CTO and type C lesions other than CTO.

In the present era, the success of $\mathrm{PCI}$ in type $\mathrm{C}$ lesions is improved to 90 to $92 \%{ }^{8,9}$ However, there are limited studies comparing the periprocedural outcomes between male and female patients. In our study, in females the most common mode of presentation is ACS whereas in males the presentation of CSA or ACS is nearly equal. Mean triglyceride levels were more in males compared with females. Mean hemoglobin concentration was low in females. Mean eGFR was lower in females compared with males. Complex lesions were more common among males. Complication rate was also low with success rate of $87.5 \%$ in the present study. There was no difference in periprocedural complications between the female and male patients.

\section{Conclusion}

PCI of type $C$ lesions presented a good success rates and low complication rates in both females and males and are comparable.

\section{References}

1 Ryan TJ, Faxon DP, Gunnar RM, et al. Guidelines for percutaneous transluminal coronary angioplasty. A report of the American College of Cardiology/American Heart Association Task Force on Assessment of Diagnostic and Therapeutic Cardiovascular Procedures (Subcommittee on Percutaneous Transluminal Coronary Angioplasty). Circulation 1988;78(02):486-502

2 Smith SC Jr, Feldman TE, Hirshfeld JW Jr, et al; American College of Cardiology/American Heart Association Task Force on Practice Guidelines; American College of Cardiology/American Heart Association/Society for Cardiovascular Angiography and Interventions Writing Committee to Update the 2001 Guidelines for Percutaneous Coronary Intervention. ACC/AHA/SCAI 2005 Guideline Update for Percutaneous Coronary Intervention-summary article: a report of the American College of Cardiology/American Heart Association Task Force on Practice Guidelines (ACC/AHA/SCAI Writing Committee to Update the 2001 Guidelines for Percutaneous Coronary Intervention). Circulation 2006;113(01):156-175

3 Ellis SG, Vandormael MG, Cowley MJ, et al; Multivessel Angioplasty Prognosis Study Group. Coronary morphologic and clinical determinants of procedural outcome with angioplasty for multivessel coronary disease. Implications for patient selection. Circulation 1990;82(04):1193-1202

4 Tan K, Sulke N, Taub N, Sowton E. Clinical and lesion morphologic determinants of coronary angioplasty success and complications: current experience. J Am Coll Cardiol 1995;25(04):855-865

5 Zaacks SM, Allen JE, Calvin JE, et al. Value of the American College of Cardiology/American Heart Association stenosis morphology classification for coronary interventions in the late 1990s. Am J Cardiol 1998;82(01):43-49

6 Zaacks SM, Klein LW. The AHA/ACC task force criteria: what is its value in the device era? American Heart Association/American College of Cardiology. Cathet Cardiovasc Diagn 1998;43(01):9-10

7 Krone RJ, Laskey WK, Johnson C, et al; Registry Committee of the Society for Cardiac Angiography and Intervention. A simplified lesion classification for predicting success and complications of coronary angioplasty. Am J Cardiol 2000;85(10):1179-1184

8 Danek BA, Karatasakis A, Karmpaliotis D, et al. Development and validation of a scoring system for predicting periprocedural complications during percutaneous coronary interventions of chronic total occlusions: the Prospective Global Registry for the Study of Chronic Total Occlusion Intervention (PROGRESS CTO) Complications Score. J Am Heart Assoc 2016;5(10):e004272

9 Christopoulos G, Wyman RM, Alaswad K, et al. Clinical Utility of the Japan-Chronic Total Occlusion Score in Coronary Chronic Total Occlusion Interventions: results from a multicenter registry. Circ Cardiovasc Interv 2015;8(07):e002171 